\title{
M-health Tools Utilization of Tele-home Healthcare Services for Diabetes Management Among Youth in Kigali City.
}

\author{
Jean de Dieu Uwimana ${ }^{1 *}$, Jacqueline Nyirandegeya ${ }^{2}$, Emile Nisingizwe ${ }^{3}$ \\ ${ }^{1}$ Simulation and Clinical skills center, College of Medicine and Health Sciences, University of Rwanda \\ ${ }^{2}$ Iranzi Clinic, Kigali, Rwanda \\ ${ }^{3}$ Research and Innovation Unit, College of Medicine and Health Sciences, University of Rwanda
}

*Corresponding author: Jean de Dieu Uwimana. Simulation and Clinical skills center, College of Medicine and Health Sciences, University of Rwanda, Remera Campus, KG 11 Ave, 47, Kigali, Rwanda. Email: uwimana790@gmail.com

\begin{abstract}
Background

Self-care of diabetes for youth requires a daily self-active participation, which is complex and demanding. Effective patient engagement through technology tools may bring about compliance to healthcare 24 hours/ 7 days which minimises the diabetes complications and clinicians overload.

Objective

This study aimed to assess M-health tools utilization of tele-home healthcare services for diabetes management among youth in Kigali City.

Method

This cross-sectional study was conducted among the Rwanda Diabetes Association members. The study populations were youth diabetic patients residing in Kigali city. With simple random sampling, self-administered questionnaire was used to collect data for 122 participants. The raw data was entered into the Statistical Package for the Social Sciences (SPSS: 20) to perform descriptive and inferential statistics in data analysis.

\section{Results}

The mobile telephone is highly used in healthcare by participants $(\geq 80 \%)$ with its functions such as Short Message Services, and the voice call is more useful $(\geq 87 \%)$. Furthermore, occupation and education level of diabetic youth do not have significance influence $(p=0.825$ and $\mathrm{p}=0.751$ ) over the use of a mobile telephone in healthcare. Radios and televisions are mostly used in healthcare education $(93.5 \%)$.

\section{Conclusions}

Tele-home healthcare is practised in Rwanda but dominated by store and forward system. Mobile telephone, radio and television are mostly used whereas emails and social media are slowly used.

Rwanda J Med Health Sci 2019;2(3):213-219.
\end{abstract}

Keywords: m-health, Tele-home, Healthcare service, and youth.

\section{Introduction}

Nowadays, Information Communication Technology (ICT) has been pivotal in healthcare service improvement. [1] The benefits of technology in healthcare delivery have been documented for synchronization of healthcare services in general and for chronic diseases management in particular. [2] Technology ensures the healthcare continuum with minimum cost. Thus, it not only reduces travel expenses and waiting time, but it also improves equity of healthcare access in remote areas and may lead to patients' satisfaction. [3]

Mobile-health care has strengthened self-care of diabetes patients through direct patient self-report of physi- ological changes taken at home or at workplace to the health professionals. [4] Self-report uses store and forward system (asynchronous) via logbook recording, short message, multimedia messaging or emailing.[3] It may also be synchronous via real-time system (synchronous) in which the patient interact with health professional through video-conferencing, mobile phone call and social media chat.[3,5,6]

Synchronous and asynchronous methods are primarily known to reduce healthcare cost through decreasing readmission, reduction of morbidity, frequency and length of hospital stay and mortality.[3] Hence, these methods improve efficiency in management of chronic diseases and data exchange among concerned health profession- 
als, which drops down waiting time for a specialist appointment. [2,7]

The management of diabetes among Rwandan youths has been taken as crucial issues by Rwanda Diabetes Association (RDA) in order to improve the wellbeing of diabetic youth. RDA as private organization established a diabetes specialized clinic in Kigali. The main services of the clinic are the provision of information on diabetes management, training health care professionals and diabetes patients towards self-care ,behavior change, free consultation, supply of drugs, gluco-meter and its accessories.[8]

However, despite the commitment of Rwandan government to ensure good health for citizen, through the uses of appropriate technology and innovations in context of scarce resources, the extent of technology use in diabetes management is still unknown. $[9,10]$ This paper focuses on assessment of M-health tools utilization of tele-home healthcare services for diabetes management among youth, identifying the existing tele-home healthcare framework for youth diabetes management and identifying technologies currently used by diabetic youth for home- patient centered care in diabetes management in Kigali.

\section{Methods}

\section{Study design}

A descriptive cross-sectional survey was performed to assess M-health tools utilization of tele-home healthcare services for diabetes management among youth in Kigali City. The target population was Rwanda Diabetes Association (RDA) youth members diagnosed with diabetes.

\section{Sample size}

The TARO Yamane formula $\left(\mathrm{n}=\mathrm{n} / 1+\mathrm{n}(\mathrm{e})^{2}\right.$, level of precision $=5 \%$ ) was used to obtain a sample size of 122 participants' members of Rwanda Diabetes Association from 176 youth member residing in Kigali city ( $\mathrm{n}=$ $\left.176 / 1+176(0.05)^{2}=122\right)$. The Simple random sampling was used since all type 1 diabetes patients, members of Rwanda Diabetes Association, living in Kigali had equal chance to participate in this study.

\section{Research instrument}

A self-administered questionnaire was used for collecting data for this study. The questionnaire was developed with reference to literature focusing on tele home care technologies $[5,6,11,12]$ and the components were demographic characteristics and the utilization of ICT tools available in Rwanda.

\section{Data analysis}

The collected data was digitalized and cleaned up in Microsoft Excel software whereas the statistical analysis was done by SPSS version 21. Descriptive statistics were used to analyze collected data while chi-square test was performed to determine the association between variables. In addition, statistical tests were taken as significant when $\mathrm{p}<0.05$.

\section{Ethical considerations}

The Approval No: UR/RECC/156/2014 for conducting this study was obtained from the Research Ethics and Consultancy Committee of University of Rwanda, College of Medicine and Health Sciences which became Institutional Review Board. The researcher had explained to the participants the aim, the benefits of the study to the participants in particular and to the community in general. Finally, the participants voluntarily signed an informed consent form prior to participating in the study. The investigator respected the confidentiality and anonymity of the data.

\section{Results}

\section{Demographic profile}

The demographic profile of participants shows that $59 \%$ were female. The mean age was 20.3 years with standard deviation of 3.7 and the majority of the participants (52.5\%) were 20 years old and below. With regard to participants' level of education, $(70.5 \%$ had secondary and higher education while $41 \%$ were students, $34.4 \%$ were employed with unemployed participants reaching $24.6 \%$ (Table 1).

Table1. Demographic characteristics

\begin{tabular}{llll}
\hline Variable & & \multicolumn{2}{l}{ Frequency } \\
\hline \multirow{4}{*}{ Sex } & Female & 72 & 59 \\
& Male & 50 & 41 \\
& Total & 122 & 100 \\
\hline Age & $\leq 20$ & 64 & 52.5 \\
(mean=20.3 & $21-35$ & 58 & 47.5 \\
SD=3.7) & Total & 122 & 100 \\
\hline \multirow{4}{*}{ Education } & Primary \& lower & 36 & 29.5 \\
& Secondary \& above & 86 & 70.5 \\
& Total & 122 & 100 \\
\hline \multirow{4}{*}{ Occupation } & Student & 50 & 41.0 \\
& Employed (public, private, & 42 & 34.4 \\
& self, informal) & 30 & 24.6 \\
& Unemployed & 122 & 100 \\
\hline
\end{tabular}

\section{Existing Tele-home healthcare framework for youth diabetes management in Rwanda}

The figure 1 shows that the patients collect their home measurements and record them in the logbook, and then they report those findings to clinicians during quarterly visit done by clinicians' team at the nearest district hospi- 
tal, or the patients meet the clinicians at Fraternity clinic (face to face communication). Furthermore, the patients combine reporting via logbook by the synchronous and asynchronous systems via technology tools such as short text messages (SMSs), voice calls, emails and social media. The use of ICT tools by patients to communicate their home measurements does not require any physical contact between patients and the clinician (indirect communication). The clinicians also provide healthcare support for the patients without physical contact through the channels used by patients.

The following diagram of tele-home healthcare framework was developed to simplify the existing interaction and communication between diabetic youth and the healthcare providers. The contents were drawn from responses gathered from the instrument I used to collect data.

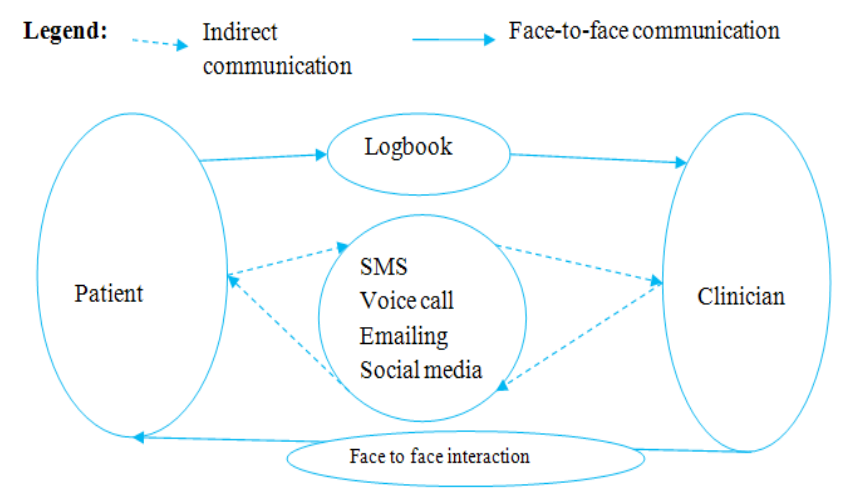

Figure 1. Tele-home healthcare framework This figure shows the existing tele-home healthcare framework of youth diabetes management in Kigali city. The diabetic youth interacts with health care provider through face to face communication by coming to health facility or bringing the logbook records to healthcare provider directly. On the other side, indirect communication is characterized by measurement of the glucose level and other vital signs at home record and transmitting them later to healthcare team through SMS, voice call, emailing or social media.

This study showed that most of the participants possess a glucometer at their residence $(99.2 \%)$ comparatively to thermometer $(27.7 \%)$ and blood pressure machine $(13.2 \%)$ home possession (Table 2). The home measurement report is dominated by store and forward method through logbook $(93.4 \%)$, short message text $(22.3 \%)$ and chatting through social media (4.1\%), whereas realtime vital signs reporting is done only through voice call $(69.4 \%)$ (Table 2).

Table 2. Self-care tools, reporting means of home findings and healthcare education at home

\begin{tabular}{|c|c|c|c|}
\hline & & $\begin{array}{ll} & \text { Yes } \\
\text { n } \quad(\%)\end{array}$ & $\begin{array}{ll} & \text { No } \\
\text { n } \quad(\%)\end{array}$ \\
\hline \multirow{3}{*}{$\begin{array}{l}\text { Self-care man- } \\
\text { agement tools }\end{array}$} & Glucometer possession $(n=121)$ & $120(99.2 \%)$ & $1(0.8 \%)$ \\
\hline & BP machine possession $(n=121)$ & $16(13.2 \%)$ & $105(86.8 \%)$ \\
\hline & Thermometer possession $(\mathrm{n}=119)$ & $33(27.7 \%)$ & $86(72.3 \%)$ \\
\hline \multirow{5}{*}{$\begin{array}{l}\text { Reporting the } \\
\text { findings from } \\
\text { patient home }\end{array}$} & Logbook record $(n=121)$ & $113(93.4 \%)$ & $8(6.6 \%)$ \\
\hline & Calling health professionals $(n=121)$ & $84(69.4 \%)$ & $37(30.6 \%)$ \\
\hline & Sending sms to health professionals $(n=121)$ & $27(22.3 \%$ & $94(77.7 \%)$ \\
\hline & Emailing to health professionals $(\mathrm{n}=121)$ & $4(3.3 \%)$ & $117(96.7 \%)$ \\
\hline & Chatting with health professionals $(n=121)$ & $5(4.1 \%)$ & $116(95.9 \%)$ \\
\hline \multirow{6}{*}{$\begin{array}{l}\text { ICT tools used } \\
\text { in healthcare } \\
\text { education at } \\
\text { home }\end{array}$} & Radio post $(\mathrm{n}=108)$ & $101(93.5 \%)$ & $7(6.5 \%)$ \\
\hline & Television post $(\mathrm{n}=106)$ & $61(57.5 \%)$ & $45(42.5 \%)$ \\
\hline & Social media $(n=106)$ & $21(19.8 \%)$ & $85(80.2 \%)$ \\
\hline & Emailing ( $n=106)$ & $11(10.4 \%)$ & $95(89.6 \%)$ \\
\hline & Mobile telephone $(n=106)$ & $54(44.3 \%)$ & $52(42.6 \%)$ \\
\hline & Other ICT tools $(\mathrm{n}=112)$ & $18(14.8 \%)$ & $104(85.2 \%)$ \\
\hline
\end{tabular}


Technologies currently used by diabetic youth for home-patient centered care for diabetes management in Kigali city.

This study indicates that $96.7 \%$ of participants possess a mobile telephone, $41.2 \%$ use social media, $40.8 \%$ use internet searching whereas $39.5 \%$ use email. Regarding the use of ICT in healthcare, most of the participants frequently use the mobile telephones $(86.7 \%)$, following by internet searching $(51.9 \%)$ then social media $(41.2 \%)$ and finally $22.2 \%$ use emailing system (Table 3). Furthermore, the chi square test showed that there is no significant association between education level of participants and the use of mobile phones in healthcare services $\mathrm{p}=0.751$, also occupation of participants like being student, public/private servants or unemployed does not have significant association with the use of mobile phones in healthcare services $\mathrm{p}=0.825$, (Table 4). The data presented in Table 2 showed that radio was the most channel used by patients in health education programs 108 (93.5\%), whereas emailing, other channels (iPod, YouTube, city flat screen, etc.) and social media were less used.

Table 3. Use of communication technology tools in healthcare services by diabetic youth

\begin{tabular}{lrr}
\hline & $\begin{array}{r}\text { Frequently } \\
\mathbf{n}\end{array}$ & \multicolumn{2}{c}{ Rarely } \\
& \multicolumn{1}{c}{$\mathbf{( \% )}$} \\
\hline Mobile telephone $(\mathrm{n}=120)$ & $104(86.7)$ & $16(13.3)$ \\
Internet searching $(\mathrm{n}=52)$ & $27(51.9)$ & $25(48.2)$ \\
Email $(\mathrm{n}=45)$ & $10(22.2)$ & $35(77.8)$ \\
Social media $(\mathrm{n}=51)$ & $21(41.2)$ & $30(58.8)$ \\
Other ICT tools $(\mathrm{n}=26)$ & $4(15.4)$ & $22(84.6)$ \\
\hline
\end{tabular}

Table 4. Association between Education Level and occupation of Participants and the use of mobile phone in healthcare services

Mobile telephone services in healthcare

\begin{tabular}{|c|c|c|c|c|}
\hline & & $\begin{array}{c}\text { Frequently } \\
\mathrm{n} \quad(\%)\end{array}$ & $\begin{array}{c}\text { Rarely } \\
\text { n }(\%)\end{array}$ & P-value \\
\hline \multirow{3}{*}{ Occupation } & Student & $43(35.8 \%)$ & $6(5.0 \%)$ & \multirow{3}{*}{0.825} \\
\hline & Employed & $35(29.2 \%)$ & $7(5.8 \%)$ & \\
\hline & Unemployed & $26(21.7 \%)$ & $3(2.5 \%)$ & \\
\hline \multirow{2}{*}{$\begin{array}{l}\text { Education } \\
\text { level }\end{array}$} & Primary & $30(25.0 \%)$ & $74(61.7 \%)$ & \multirow[b]{2}{*}{0.751} \\
\hline & $\begin{array}{l}\text { Secondary } \\
\text { and above }\end{array}$ & $4(3.3 \%)$ & $12(10.0 \%)$ & \\
\hline
\end{tabular}

\section{Discussion}

\section{Demographic profile}

This study shows that most of the participants are 20 years old and below (52.5\%). As long as Rwanda counts $63 \%$ of $14-35$-year-olds who are in the labor force,[13] some researchers recommended that it is crucial to avoid unnecessary travels and queuing at clinician office for this age group to seek the healthcare services which can be gained at workstation or at home as they are the active population. [14] It has been illustrated that the diabetes home management can reduce readmissions, long hospitalization and competition to nursing healthcare at health facilities which are still scarce in developing countries. [7,15-17] Thus, the telehome care for youth diabetes will promote their wellbeing physically and with cost effectiveness while seeking for healthcare services.

The gender proportion of participants showed that the number of females is greater than the number of males, $59 \%$ against $41 \%$. These results are contrary to findings of the study done in Brazil where males were more numerous than females $60.6 \%$ and $39.3 \%$ respectively) [18]. This correlates with the national gender proportion where females are more than males, i.e. $51.8 \%$ against 48.2\%. [19] Though, the diabetes management should be based on gender consideration as it was reported that the female had better knowledge than male about diabetes management.[18]

As far as Rwanda emphasises on youth forces, schooling is the first pillar to construct a nation. But diabetes in youth can impede education outcome because its management requires 24 hours a day, seven days a week.[14] As a solution to this impediment, M-health tools may help to monitor and manage glucose in the classroom promptly and consequently, alleviate the delay in monitoring and management of diabetes among the scholars. [20] This study finds that most of the participants have secondary education and higher level $70.5 \%$ and $41.0 \%$ are students, Rwanda Diabetes Association supports the diabetic youths to become independent and healthcare decision makers on their health management without queuing up at health facilities. [8] This intervention allows the students to stay at their schools while assuring diabetes care jointly with care received at home in order to avoid absenteeism of diabetes students.[21]

Current tele-home healthcare framework for teenagers and youth diabetic patient management in Rwanda

Rwanda Diabetes Association has settled various plans in order to respond to the needs of Rwanda diabetic patients especially the youth, by providing some free selfcare tools and helping the adult people to get self-care tools at a lower price. The association also helps to train diabetes patients, health professionals and pro-acted for diabetes treatment innovations.[8]

Indeed, as it is illustrated in figure 1, the youth diabetic patients have the ability to communicate with clinician team through various means. 
The youth with diabetes takes vital sign at home (blood sugar) record into the logbook and report the result to the clinician by face to face or Short Text Message (SMS), voice calls, emailing and social media. The means used by patients are followed by the clinician to provide any healthcare support.

Consequently, the Rwanda Diabetes Association (RDA) promotes M-health by availing two nurses responsible to respond the voice call or short text message (SMS) 24 hours per day, 7 days a week and visiting the diabetes face- to - face at a quarterly basis in district hospitals where the clinician team could assess the home measurements recorded in patient logbook.[8]

\section{Self-management and technology tools used by home diabetic patient centred care system in Rwanda}

The key element of youth diabetes management is active participation of the patient in bloodstream glucose control.[21] This control could not be successful without vital sign materials at patient's residence. Since glucometers are given free of charge by Rwanda Diabetes Association, the availability of glucometer at home is a first pillar of self-care of diabetes.

However, the low use of other vital sign measurements at home such as blood pressure machine, thermometer and scale impede tight self-control of diabetes and other associated complications such as cardiovascular diseases, malnutrition, and improvement of lifestyle for youth who are normally occupied by schooling and productive business.[22] Hence, reporting vital signs taken at home is a milestone of $\mathrm{m}$-health to manage diabetes. Though, the means of reporting home findings are dominated by store and forward methods by which the patients record their measurement first into logbook, and later, they report them to healthcare providers during clinicians' visits at their health facilities.

However, other technology tools can sometimes be used to transmit home recorded data like Short Message Services (SMS) or call. These practices had shown inefficacy to self-management of diabetes and its complications as was illustrated in the study done in France: 'reporting by logbook was considered with doubtable efficacy since data could be wrongly filled, incorrectely recorded or delayed to be reported to clinicians'.[23] As a consequence, the clinician can intervene on wrongly findings or delay supporting the patients in a critical situation. [24]

Indeed, automatic reporting home measurement using mobile phones could be enhanced instead of storing and forwarding system. The combination of vital sign materials and portable telecommunication at patient's home offers channels for propagating a message on critical vital sign findings, risk factors, and long-term complications to the clinician team.[15]Thus, the sustainable solution could be directed to the use of a personal wireless system synchronizing all required patient information and facilitate the mutual exchange between patient and clinician.[25]. Hence, automated reporting system could be promoted regardless the education level of diabetic youths in RDA.

However, automated reporting system requires minimum technology tools. This study revealed various technology tools used by youth diabetic patients in RDA on daily basis. Among them, mobile phones are highly used, these results are aligned with the national mobile phone penetration in Rwanda, particularly in Kigali where $79.6 \%$ of the residents own mobile telephone.[26] Thus, this technology penetration rate among youth diabetes is a great asset to change the ways health care providers are using technology through integrating tele-home care in their framework.

This tremendous use of a mobile telephone in healthcare provision is an indicator of its higher user friendliness. $[15,27]$ In this line, the studies revealed that mobile telephone accessibility and user friendliness, [27] allow youth diabetic patients to feel comfortable to use it when calling or sending an SMS for healthcare purposes. Simple mobile telephone services (voice call and SMS) are used more than other telecommunication means available in Rwanda, and this stressed that voice call and SMS may be better and simpler medium of communication in healthcare services, especially in diabetes self-management process for people with poor resources in developing countries. Consequently, any intervention applied to a mobile phone will be warmly welcomed with high success depending on experience to use mobile phone features as there is no influence of education level and occupation domain over the use of a mobile telephone in healthcare services $(p=0.751 ; p=0.825)$.

Even though youth diabetic patients are aware of the importance of home self-management, healthcare education at home is one of success inducer and cannot exist without Information Communication Technology tools. Health education through ICT tools is a solution for youth to keep them at school or workstation considering that face-to-face health education, traditional intervention consumes time and money for both patients and healthcare providers and have not been successful in reaching all patients at the right time.[28]

This study found that most of the participants benefit from healthcare education at home or workstation through radio post rather than other telecommunication channels like television post, mobile telephone, emailing and chatting through social media. The low use of these channels may reduce disease awareness as other studies illustrated that 'Internet technologies strengthen 
diabetic patient self-management through increased disease awareness, health education, and social support.[16] Though, healthcare education through radio needs to be beefed up by visual and movie technology tools as other studies have shown that learning through seeing and doing is better than learning by hearing. 'If I hear it, I forget it; if I see it, I remember it; if I do it, I know it' old Chinese saying.[29] In this regard, videoconference, television, emailing, and social media can be more effective in health education because simulation practice on diabetes management can be played through television, sent on email, or posted on wall of patient group social media account in order to increase skills and knowledge in self-management at home.[30]

\section{Conclusion}

The existing tele-home healthcare framework for youth diabetes management in Kigali city is dominated by store and forward system through which the youth diabetes record the home measurement data and forward findings later to healthcare providers for further interventions. Hence, to transmit home findings, the youth diabetes use different ICT tools; mostly they use the mobile telephone to interact with healthcare provider team and radio post for healthcare education at resident or workstation. However, there is no synchronised system to facilitate remote patient and clinician automatic interaction. Furthermore, email and social media useful to interact with healthcare provider team are slowly used in both reporting the home measurement as well as in diabetes education.

\section{Recommendation}

RDA and its partners are recommended to synchronize the reporting of home measurements via mobile phone application as clinical monitoring and management tool for diabetic patients. In addition, healthcare education through radio, televisions and other ICT tools could be strengthened in order to boost diabetes self-management awareness in Rwanda.

\section{Acknowledgement}

The authors would like to offer special thanks to their beloved families for their moral and spiritual support. They also want to extend their gratitude to the Government of Rwanda through its Institutions such as University of Rwanda/ College of Medicine and Health sciences and Rwanda Education Board for their academic and financial support. They also recognize the support from Rwanda Diabetes Association during this study.

\section{Authors'contribution}

All authors have contributed in writing of this article.

\section{Conflict of interest}

No conflict of interest

This article is published open access under the Creative Commons Attribution-NonCommercial NoDerivatives (CC BYNC-ND4.0). People can copy and redistribute the article only for noncommercial purposes and as long as they give appropriate credit to the authors. They cannot distribute any modified material obtained by remixing, transforming or building upon this article. See https://creativecommons.org/licenses / by-nc-nd/4.0/

\section{References}

1. Ministry of Health/ Government of Rwanda. Third Rwandan Health Sector Strategic Plan July 2012-June 2018. 2012.

2. Elek Dinya TT. Health Informatics : e-Health and Telemedine. 2013;

3. McLean S, Sheikh A, Cresswell K, Nurmatov U, Mukherjee M, Hemmi A, et al. The impact of telehealthcare on the quality and safety of care: A systematic overview. PLoS One. 2013;8.

4. Nsereko E, Bavuma C, Tuyizere M, Ufashingabire C, Jmv R, Yamuragiye A. Illness Perceptions and Depression in Relation to Self-care Behaviour among Type 2 diabetes Patients in a Referral Hospital in Kigali-Rwanda. Rwanda j Heal sci. 2013;2:1-9.

5. Cocosila M, Coursaris C, Yuan Y. M-healthcare for patient self-management: a case for diabetics. Int J Electron Healthc. 2004;1:221-41.

6. Chan V, Ray P, Parameswaran N. Mobile e-Health monitoring: an agent-based approach. IET Commun, Vol 2, No 2, Febr 2008. 2008;2:223-230.

7. Qiang et al. Mobile Applications for the Health Sector. $2011 ; 101$.

8. Rwanda Diabetes Association. Our history. 2014.

9. Government OF Rwanda. The constitution of the Republic of Rwanda of 2003 revised in 2015. Off Gaz. Kigali; 2015;158.

10. MOH Rwanda. Health Sector Policy. 2015; 
11. Montori VM, Helgemoe PK, Guyatt GH, Dean DS, Leung TW, Smith S a., et al. Telecare for Patients With Type 1 Diabetes and Inadequate Glycemic Control: A randomized controlled trial and meta-analysis . Diabetes Care. 2004;27:1088-94.

12. West D, Branstetter DG, Nelson SD, Manivel JC, Blay J-Y, Chawla S, et al. How Mobile Devices are Transforming Healthcare. BrookingsEdu. 2012;18:1-38.

13. National Institute of Statistics of Rwanda. Socioeconomic Status of Youth. Kigali; 2014.

14. Rapp JA, Dimmick BL. Legal Rights of Students with Diabetes. 1st ed. Quincy, Illinois: American Diabetes Association; 2007.

15. Ajay VS, Prabhakaran D. The Scope of Cell Phones in Diabetes Management in. J Diabetes Sci Technol. 2011;5:778-83.

16. Connie C, Kaufman D. A technology selection framework for supporting delivery of patient-oriented health interventions in developing countries. J Biomed Inform. Elsevier Inc.; 2010;43:300-6.

17. Dinesen B, Gustafsson J, Nøhr C, Kjærandersen S, Sejersen H, Toft E. Telehomecare technology across sectors: claims of jurisdiction and emerging controversies. Int J Integr Care. 2007;7:43.

18. Lemes Dos Santos PF, Dos Santos PR, Ferrari GSL, Fonseca GAA, Ferrari CKB. Knowledge of diabetes mellitus: Does gender make a difference? Osong Public Heal Res Perspect. 2014;5:199-203.

19. National Institute of Statistics of Rwanda. 2012 Population and housing census. Report on the provisional results. Kigali; 2012.

20. American Diabetes Association. Diabetes care in the school and day care setting. Diabetes Care. 2013;36.

21. Vermont Department of Health. Recommendations for Management of Diabetes for Children in School. Burlington: 108 Cherry Street, VT 05402,
802-865-7708: Vermont Department of Health; 2013.

22. Shrivastava SR, Ramasamy J. Role of self-management of diabetes mellitus. J Diabetes Metab Disord. $2013 ; 12$.

23. Klonoff DC. Improved outcomes from diabetes monitoring: the benefits of better adherence, therapy adjustments, patient education, and telemedicine support. J Diabetes Sci Technol. 2012;6:486-90.

24. Franc S, Dardari D, Boucherie B, Daoudi A. Telemedicine in diabetes: current results and perspectives. Médecine des Mal Métaboliques. 2010;4:274-86.

25. Rigla M. Smart Telemedicine Support for Continuous Glucose Monitoring: The Embryo of a Future Global Agent for Diabetes Care. J Diabetes Sci Technol. 2011;5:63-7.

26. National Institute of Statistics of Rwanda. Integrated Household Living Conditions survey 3 (EICV 3) ,. Integrated Household Living Conditions survey. Kigali; 2012.

27. Department of Economic and Social Affairs. Compendium of ICT Applications on Electronic Government Mobile Applications on Health and Learning. New York: United Nations United Nations. New york: United Nations; 2007.

28. Goodarzi M, Ebrahimzadeh I, Rabi A, Saedipoor B, Jafarabadi M. Impact of distance education via mobile phone text messaging on knowledge, attitude, practice and self efficacy of patients with type 2 diabetes mellitus in Iran. J Diabetes Metab Disord. 2012;11:10.

29. Hesperian. Learning through seeing, Doing, Thinking. In helping Health workers Learn. 2012;11.

30. Society for Simulation in Healthcare. Simulation. 2014. 